\title{
CORPUS Corpus
}

Archivos virtuales de la alteridad americana

Vol 1, No 2 | 2011

Julio / Diciembre 2011

\section{Pueblos indígenas. Racismo, genocidio y represión.}

\section{Liliana Tamagno}

\section{OpenEdition \\ Journals}

Electronic version

URL: http://journals.openedition.org/corpusarchivos/1164

DOI: 10.4000/corpusarchivos. 1164

ISSN: 1853-8037

\section{Publisher}

Diego Escolar

\section{Electronic reference}

Liliana Tamagno, «Pueblos indígenas. Racismo, genocidio y represión. », Corpus [En línea], Vol 1, No

2 | 2011, Publicado el 30 diciembre 2011, consultado el 30 abril 2019. URL : http://

journals.openedition.org/corpusarchivos/1164 ; DOI : 10.4000/corpusarchivos.1164

This text was automatically generated on 30 April 2019.

Licencia Creative Commons: Atribución-NoComercial 2.5 Argentina (CC BY-NC 2.5 AR) 


\title{
Pueblos indígenas. Racismo, genocidio y represión.
}

\author{
Liliana Tamagno
}

\section{Introducción}

1 Antes de volcar las reflexiones que serán objeto de la discusión a que se nos convoca $-\mathrm{y}$ que entiendo como un interesante desafío- quiero expresar que atravieso un momento de particular sensibilidad personal ante lo que podríamos llamar la visibilidad de la cuestión indígena hoy. Una visibilidad que no es ajena ni a la trayectoria de lucha del movimiento indígena en su conjunto ni a los espacios generados por las políticas estatales y en particular por aplicación de la Ley 26.160, de la Resolución 4811, del Programa de Relevamiento Territorial y de la instrumentación del Consejo de Participación Indígena y que no está exenta de violentas represiones.

Observar la etnicidad como una expresión política de la identidad conlleva a comprender el campo indígena como un espacio de disputa en el que se conjugan -sin solución de continuidad- diversidad y desigualdad, etnicidad y clase, lógica de la acumulación y lógica de la reciprocidad (Bartolomé Miguel 1987; Joao Pacheco de Oliveira 1999; Tamagno 1986,1996, 2001, 2008). Es por ello que mi trayectoria de investigación sobre la cuestión indígena me insta a detenerme en el análisis de los alcances y los límites de una coyuntura particular que comienza finalizada la Dictadura Militar 1976-1983 y en la que reemergen planteos realizados en las décadas de 1960 y 1970, que vuelven a tener actualidad en el contexto de las aperturas políticas representadas por los gobiernos constitucionales de la región y sus respectivas articulaciones. Entiendo además que los acontecimientos deben ser pensados inexorablemente en términos de "larga duración" (Braudel 1969) teniendo en cuenta no sólo las coyunturas en las que emergen, sino y al mismo tiempo las condiciones estructurales en las que éstas se gestan y desarrollan. Ello me habilita a traer a este espacio de reflexión y discusión parte del texto de la "Primera Declaración de Barbados por la liberación del indígena”, redactada por antropólogos entre los días 25 y 30 de enero de 1971, en el marco del Simposio sobre la Fricción 
Interétnica en América del Sur", luego de analizar los informes presentados acerca de la situación de las poblaciones indígenas/tribales de países del área. Esta declaración es uno de los momentos síntesis en que se interpreta y se evalúa la situación de los pueblos indígenas, al mismo tiempo que se realizan recomendaciones a los estados, a las misiones religiosas y a los antropólogos:

Los indígenas de América continúan sujetos a una relación colonial de dominio que tuvo su origen en el momento de la conquista y que no se ha roto en el seno de las sociedades nacionales. Esta estructura colonial se manifiesta en el hecho de que los territorios ocupados por indígenas se consideran y utilizan como tierras de nadie abiertas a la conquista y a la colonización. El dominio colonial sobre las poblaciones aborígenes forma parte de la situación de dependencia externa que guarda la generalidad de los países latinoamericanos frente a las metrópolis imperialistas. La estructura interna de nuestros países dependientes los lleva a actuar en forma colonialista en su relación con las poblaciones indígenas, lo que coloca a las sociedades nacionales en la doble calidad de explotados y explotadores. Esto genera una falsa imagen de las sociedades indígenas y de su perspectiva histórica, así como una autoconciencia deformada de la sociedad nacional. Esta situación se expresa en agresiones reiteradas a las sociedades y culturas aborígenes, tanto a través de acciones intervencionistas supuestamente protectoras, como en los casos extremos de masacres y desplazamientos compulsivos, a los que no son ajenas las fuerzas armadas y otros órganos gubernamentales. Las propias políticas indigenistas de los gobiernos latinoamericanos se orientan hacia la destrucción de las culturas aborígenes y se emplean para la manipulación y el control de los grupos indígenas en beneficio de la consolidación de las estructuras existentes. Postura que niega la posibilidad de que los indígenas se liberen de la dominación colonialista y decidan su propio destino. Ante esta situación, los Estados, las misiones religiosas y los científicos sociales, principal-mente los antropólogos, deben asumir las responsabilidades ineludibles de acción inmediata para poner fin a esta agresión, contribuyendo de esta manera a propiciar la liberación del indígena.

En este sentido retomo la propuesta de la necesidad de un "dialogo con la academia" y un "dialogo con el campo" (Tamagno 2001). Aludiendo en el primer caso a un repensar crítico, no sólo de las prácticas académicas sino de las narrativas con las que dichas prácticas se expresan textualmente; un pensar que se profundiza en un diálogo cotidiano, intenso y por momentos incluso silencioso, ya que como es sabido no todo puede plasmarse en términos académicamente correctos cuando los sentimientos bullen y el dolor de los otros se convierte en nuestra desazón frente a violaciones de los derechos indígenas, que no deberían suceder en tiempos en que nos acercamos a cumplir 40 años de gobiernos constitucionales y los términos "democracia" y "derechos humanos" habitan los relatos que sostienen las políticas sociales en general y las políticas indigenista en particular. En el segundo caso y valorando significativamente el espacio de reflexión/discusión para el que se nos convoca en esta oportunidad, aludo a pensar en términos de diálogo con los referentes indígenas con los que trabajamos y con las situaciones que se desarrollan en el contexto de la observación participante/participación objetivante (Bourdieu y otros 1975), en la necesidad de analizar tanto los alcances y los límites de las políticas indigenistas actuales, como los alcances y los límites de nuestras propias narrativas al respecto.

5 Cabe señalar, teniendo en cuenta el impacto de toda legislación indígena (Tamagno 1996), que las políticas indigenistas devenidas de la aplicación de los marcos legales antes 
citados han generado espacios de reconocimiento y legitimación y han posibilitado condiciones materiales para que las presencias y las demandas de los pueblos indígenas se expresen, contribuyendo a que la sociedad en su conjunto se sensibilice por una cuestión largamente negada, silenciada, descalificada. Son ejemplo de ello la movilización generada por el proyecto de relevamiento territorial y por la puesta en acción del Consejo de participación indígena; la movilización que hizo posible la multitudinaria Marcha Indígena del Bicentenario en el mes de Mayo del 2010 y la recepción de referentes indígenas en la Casa de Gobierno por parte de la Presidenta de la Nación; el espacio particularmente dedicado a lo indígena en la escenificación realizada por el Grupo Teatral Fuerza Bruta como corolario de los mismos festejos; así como también el espacio significativo que la temática indígena ocupa en la programación del Canal Encuentro del Ministerio de Educación de la Nación; esto para nombrar los que entiendo como de mayor impacto en la sociedad argentina en los últimos años.

6 Sin embargo y al mismo tiempo, no podemos dejar de reconocer que esas mismas políticas han contribuido a reproducir prácticas que habían sido, o estaban siendo, repensadas y/o revisadas por las propias poblaciones indígenas en el marco de los procesos de transformación y de las dinámicas socioculturales que los caracterizan y que han dado lugar a múltiples respuestas organizativas a lo largo de la relación con los otros conjuntos sociales que conforman la Nación. Un ejemplo de ello son las tensiones que genera al interior del campo indígena el hecho de verse conminados a convertirse en "comunidades" y a designar un "cacique" y/o de tener que re-conocer o enfrentar liderazgos que, gestados al calor de las pugnas político partidarias no representan los momentos más significativos de avances de las luchas indígenas; si es que por avance entendemos la búsqueda de autonomía y la consolidación de formas organizativas guiadas por la lógica de lo colectivo comunitario. Lógica cuya significación ha sido históricamente negada, subes-timada o descalificada (Tamagno 2001; 2010) y que aun está vigente en ciertas prácticas y representaciones que ordenan la existencia de los pueblos indígenas a pesar de las presiones en contrario de un mundo globalizado -la sociedad nacional no es ajena a ello- guiado por el individualismo, la competencia, el lucro y el enriquecimiento de algunos pocos en desmedro de las enormes carencias de muchos.

\section{Acerca de la convocatoria. El surgimiento de una pregunta}

7 Si bien el objetivo de este texto es seguir el derrotero de la guía de preguntas que se nos ha enviado me detendré en el tratamiento del término "pueblos originarios" que aparece ya en el título de las consideraciones mediante las cuales se nos convoca. Los que tenemos unos cuantos años en el tratamiento del campo de la cuestión sabemos de la casi unanimidad en el uso del término "pueblos indígenas" en nuestras producciones académicas. Basta recordar la preferencia por el término "pueblos indígenas" compartido por las producciones de la mayoría de los pensadores latinomericanos que marcaron camino en el tratamiento de la situación de las sociedades que poblaban el continente con anterioridad a la conquista y colonización - reemplazando al término “aborígenes" cuya etimología remontaba a "sin origen" y al término "indio" por connotar subestimación e inferioridad. También quiero recordar las discusiones, de profundo contenido político (político en términos antropológicos y no político partidarios, se entiende) y por lo tanto estratégico que se dieron entre quienes proponían el término 
"pueblos indígenas" haciendo referencia tanto a la variable diversidad como a la variable desigualdad y quienes proponían el término "pueblos originarios" poniendo énfasis en la diferencia, tal como quedara expresado en el panel Etnicidad y Movimientos políticos en América latina del IV Congreso Argentino de Antropología Social que tuvo lugar en la ciudad de Olavarría en 1994. Para quienes se utilizaban el término "pueblos originarios", la cuestión indígena debía resolverse internamente, prevaleciendo una postura que tenía mucho de esencialismo y que se expresaba en desdeñar toda reflexión conjunta con los no indios o con los blancos. Pensar en términos de etnicidad aparecía como excluyente de pensar en términos de clase; algo que hemos planteado no es más que una falsa antinomia (Tamagno 2001; 2008) que pretende ocultar la relación inescindible entre etnicidad y poder y entre etnicidad y economía. Me asombra y me inquieta la repentina reaparición del término "pueblos originarios" y su masificación en los medios de comunicación, sin que haya llegado a mis oídos información respecto del debate que volvió a colocarlo en escena con tanta contundencia. Consultada una referente indígena participante de la Conferencias Regional y Ciudadana de las Américas - preparatorias de la Conferencia Mundial contra el Ra-cismo, la Discriminación Racial, la Xenofobia y las Formas Conexas de Intolerancia a realizarse en Durban, Sud África- que tuviera lugar en Chile en el 2000, donde al parecer fue impuesto el término, informó que ni siquiera se dio tiempo a la discusión e interpretó que el objetivo era distraer respecto de la incorporación de la variable desigualdad en el tratamiento de la diversidad. En este sentido se me aparece casi como una contradicción pensar en términos de aniquilamiento, crímenes de lesa humanidad o genocidio y aceptar acríticamente el término "pueblos originarios" que, al menos hasta donde sé, parece haber sido impuesto desde miradas e intereses hegemónicos que pretenden escamotear del análisis la variable desigualdad.

Me pregunto qué quedó del lema "como indios nos dominaron, como indios nos liberaremos". Qué quedó de los planteos de la Segunda Reunión de Barbados en la cual los representantes del Congreso Indígena de la República Argentina se refieren a sí mismos como "indios" y enuncian como postulados fundamentales el respeto por la persona y la personalidad cultural india, a su tierra como la tierra del indio, a la personería jurídica de las comunidades indígenas, al libre empleo de los idiomas indígenas; afirmando que son el "punto de mira que empleamos para apreciar la sinceridad de las intenciones de los que no son indios que se incorporen a nuestra tarea" (Grupo de Barbados 1979:73). Me pregunto cuál es la justeza y el rigor del término "originario", cuando en tanto seres humanos todos provenimos de un origen. $\mathrm{O}$ es que sólo tienen origen los pueblos preexistentes a la conquista y la colonización?

\section{Atendiendo a los tópicos de la convocatoria}

Concibo los procesos históricos de expansión del Estado sobre los territorios y sobre las sociedades indígenas en términos de Miguel Bartolomé (1987), cuando refiere al modo en que lo que los "estados de conquista" se continuaron con los que denomina "estados de expropiación", proceso que tuvo como razón de ser la expansión de las relaciones de producción impuestas desde Europa, en función de sus propias crisis y necesidades. En la concepción del conquistador el mundo se transformó subjetivamente en uno y por lo tanto posible de ser conquistado, decidiendo sobre él y sobre sus habitantes e imponiendo una relación fatídica de inferioridad/superioridad. Un mundo creado a imagen y semejanza del dominador y su ética (Worsley 1966; Said 1978). Un estado nacional que se 
constituyó también sobre el genocidio y el etnocidio (Tamagno 2002) y promovió la ocupación del territorio, sobre el que impuso un régimen de propiedad privada para beneficio de determinados sectores, en nombre de la "civilización" y el "desarrollo"

Siguiendo esta línea argumental y en tanto, la constitución de nuestro país como República independiente, implicó un plan sistemático de expropiación de los territorio ocupados por los pueblos indígenas -que fueron diezmados, arrinconados, subestimados y abruptamente privados de continuar reproduciendo su existencia del modo en que lo realizaban en momentos anteriores a la conquista- podemos afirmar que se produjo un genocidio. Cabe aclarar que el genocidio es reconocido como delito a partir de la Convención de las Naciones Unidas para la prevención y la sanción del delito de genocidio en 1948, por lo que los antropólogos nos referimos a etnocidio, entendido como las acciones que dan lugar a la destrucción masiva de un grupo étnico, o a eliminar cualquier aspecto fundamental de su cultura y organización, como sucedió en la expansión colonial caracterizada por la ética del conquistador (Worsley) que continuó guiando el proceso de surgimiento y consolidación de la república con una mentalidad colonial (Quijano 1987; Escobar 2003). El término genocidio fue utilizado conjuntamente con el término racismo en la declaración de principios y objetivos del Congreso Indígena de la República Argentina que tuvo lugar en la Segunda Reunión de Barbados (Grupo de Barbados 1978:74-75).

11 Es por ello que propongo pensar el genocidio en su relación con el etnocidio y por lo tanto con el racismo, definido por Eduardo Menéndez (1971) como la relación social impuesta en el mundo a partir de la expansión colonial, legitimadora de la gestación, desarrollo y consolidación de las relaciones capitalistas de producción y los modos particulares de apropiación de la naturaleza y de explotación humana que éste conlleva. Un racismo que trazó y traza en términos de Edward Said (1978:315) fronteras reales entre los seres humanos entre los cuales se construyeron razas, naciones y civilizaciones, que forzaron a las poblaciones humanas a desviarse de las realidades humanas plurales, obligándolas a fijar la atención para "abajo" y para "atrás" de los orígenes que se presentan como inmutables. Un racismo que no solo se expresa en odiar negros o judíos, sino que está presente en las descalificaciones que cotidianamente justifican la explotación de unos por otros (Tamagno 2002) en los términos expresados en la Segunda Declaración de Barbados.

Respecto a las razones de elección del término genocidio/etnocidio en lugar de otras categorías jurídicas / sociales próximas, tales como masacre estatal o exterminio o crimen de lesa humanidad, habría que considerar -sobre todo desde el punto de vista jurídico- los alcances y los límites de cada una de estas denominaciones. No soy especialista en cuestiones jurídicas por lo que entiendo que no es pertinente en este caso opinar respecto de los alcances y los límites de cada uno de los términos en particular y de su operatividad; aunque es de destacar que pensando en términos antropológicos y desde el punto de vista de que toda violencia estatal es reprobable y debe ser sancionada, estos términos podrían interpretarse como sinónimos

13 Afirmamos que estamos frente a genocidio cuando las poblaciones indígenas son condenadas a vivir en total indigencia al ver abruptamente transformada su existencia frente al avance de proyectos en cuya diagramación no participan y que les son ajenos, no sólo porque no tienen en cuenta sus presencias, sino porque desconocen los valores que a pesar de todo aun las sustentan. Valores que se expresan en concepciones de vida, muerte, poder y naturaleza que son alternas a la concepción individualista que guía la expansión del capital y el desarrollo tecnológico a su servicio. Las muertes por 
desnutrición y por enfermedades que no tienen condiciones para tratar, los casos de suicidio étnico, el arrinconamiento, el desalojo y la represión cuando se rebelan y se juntan para deliberar sobre su existencia, son y continúan siendo una constante en el cotidiano de los pueblos indígenas.

Por lo tanto es falso circunscribir el etnocidio a lo ocurrido en el Siglo XIX en Argentina y en especial a lo ocurrido en la llamada Conquista del Desierto, ya que de este modo quedan en el olvido y se desconocen hechos ocurridos a lo largo de nuestra historia cercana, en que los pueblos indígenas se rebelaron para defender sus derechos y fueron violentamente reprimidos. Así lo confirman en el Chaco Argentino las represiones a los movimientos que ya a principio del siglo XX se organizaron para enfrentar las imposiciones del blanco y que aunque interpretados en términos de milenarismos fueron ver-daderos momentos de rebelión que implicaron reflexiones críticas sobre qué hacer y cómo seguir, tales como los de Napalpi en 1933, Zapallar en 1935, Rincón Bomba en 1947 (Tamagno 2009). También se ocultan -más cercanas a nuestros días- las violaciones a los derechos humanos ante la ola de desalojos de población indígena y campesino indígena que dieron lugar a la Ley 26.160; la imposibilidad de dicha norma jurídica de frenar los embates del interés privado (las amenazas para que desalojen, la usurpación violenta de territorio, la práctica constante de corrimiento de alambrados); la represión de la Comunidad Qom de La Primavera, en Formosa que tomó estado público a través de lo que se conoció como "Acampe Qom" en pleno centro de la ciudad de Buenos Aires; la muerte en condiciones sumamente confusas del referente Qom Mártires López con quien compartimos trabajo de campo y espacios académicos y por la cual se está reclamando investigación y justicia; la violación a los derechos humanos sufrida por la población Wichi de Sauzalito, en la Provincia de Chaco; la última represión en el Ingenio Ledesma; la desidia estatal frente a las traumáticas condiciones de existencia de las poblaciones Qom migrantes urbanas azotadas por la falta de trabajo digno y vivienda digna y convertidas en rehenes de toda suerte de clientelismos y/o asistencialismos, que no sólo no dan solución a dichas situaciones sino que atentan contra lo colectivo/comunitario y contra la lógica de la reciprocidad (Tamagno 2010).

Si pensamos en términos de Foucault cuando define la política como la continuidad de la guerra por otros me-dios, podemos pensar en políticas de exterminio respecto de la población indígena; políticas de exterminio que continúan en tanto no se revierte el modo de producción que los ha convertido en poblaciones totalmente empobrecidas $\mathrm{y}$ abandonadas a las presiones de los clientelismos locales (Tamagno 2001).

Siguiendo la línea argumental que estoy desarrollando y valorando las rebeliones como respuestas a las imposiciones desde lo hegemónico, hemos propuesto pensar la dinámica de las poblaciones indígenas en términos de complejos procesos de aceptación/rechazo del modelo impuesto (Tamagno 1991). En este sentido destacamos la necesidad de analizar las presencias actuales de los pueblos indígenas como presencias activas, pues activos han sido a lo largo de la historia. En este sentido entendemos que se debe ser sumamente cuidadoso para no reducir a las poblaciones indígenas a su mera condición de víctimas. Es claro que son víctimas de una sociedad altamente injusta y desigual y de constantes violaciones a los derechos humanos, pero ello no excluye valorar sus presencias a pesar de la violencia colonial, a pesar de la violencia estatal y a pesar de la violencia a la que están sometidos en el cotidiano de sus existencias. 


\section{Qué hacer?}

17 La reparación del genocidio debe ir más allá de la denuncia ya que debe comprenderse como constitutivo de las relaciones capitalistas de producción. De todos modos y como toda construcción histórica es realizada por hombres y mujeres, puede deshacerse y rehacerse y por lo tanto puede transformarse. Hay entonces acciones que pueden emprenderse en el sentido de la reparación histórica que los pueblos indígenas demandan.

Profundizar el análisis crítico respecto de la concepción hegemónica de explotación de la naturaleza y de las poblaciones humanas (avance sojero, megaminería, megaturismo).

Profundizar la crítica a la lógica individualista y liberal fundada en el lucro, la competencia y la acumulación (Sahlins 1977)

Valorar las lógicas de la reciprocidad y las lógicas comunitarias (Gordillo 1994; Tamagno 2010) presentes en las poblaciones indígenas o campesino/indígenas.

21 Eliminar el término "poblaciones vulnerables" pues impide reconocer el potencial de estas poblaciones para participar activamente en las tomas de decisiones que conduzcan a neutralizar dicho modelo de explotación, superando todo "pensamiento único".

Revisar y quebrar el estereotipo descalificador que pesa sobre las poblaciones indígenas y las miradas esencialistas que nacidas del colonialismo y de los preconceptos de Occidente en su impulso de describir pero también de dominar, aún perduran y son funcionales a la reproducción de la desigualdad; ya que abonan relatos que bajo un presunto reconocimiento y una presunta solidaridad, desdibujan y ocultan las trayectorias de lucha de los pueblos indígenas presentando su existencia a partir de imágenes bucólicas y vinculados casi ingenuamente a la naturaleza más que a la sociedad y sus tensiones. Un relato que aunque re-presenta un avance respecto del silenciamiento de etapas anteriores, impide comprender en toda su riqueza y dinámica las múltiples expresiones y las múltiples formas organizativas que presentan los pueblos indígenas y que son el resultado de síntesis particulares de la historia compartida como ciudadanos de un país al que conforman desde su gestación.

Reconocer que son ciudadanos de un país que durante décadas les negó la categoría de ciudadanos, primero jurídicamente y luego en la práctica y que por lo tanto es erróneo pensar a los pueblos indígenas como aislados de la sociedad en su conjunto, ya que nunca lo estuvieron y tampoco lo están y su existencia como integrantes de la Nación es el producto de una relación compleja entre diversidad y desigualdad.

Reconocer, por lo tanto, la representatividad política a todos aquellos líderes originados en la organización y la lucha y que son en la actualidad referentes de colectivos históricos; no forzar representatividades ni pretender hacerlas compatibles con una democracia que en la actualidad tiene muy poco de representativa y mucho de clientelar.

Se trata entonces de pensar cómo superar todos los esencialismos y por lo tanto cómo narrar y tratar a los pueblos indígenas en tanto constituyentes de la Nación Argentina y entendidos como categorías históricamente construidas, producto de procesos complejos de aceptación rechazo de los modelos que se les impusieron y se les imponen. He acuñado el término "censores de la indianidad" (Tamagno 1991) para señalar a todos aquellos que se arrogan el derecho de decir quién es indígena y quién no lo es y propongo enriquecer este planteo con los aportes de Edward Said (2003) en el sentido de destacar la 
operatividad y la funcionalidad del estereotipo "indígena" para justificar las actuales relaciones de desigualdad.

En este sentido entendemos que un eventual reconocimiento del genocidio por parte del Estado Nacional y de los estados provinciales serían un paso significativo, pues la norma legal sienta las bases del reconocimiento de la violencia sufrida, genera la posibilidad de fortalecimiento de las víctimas a partir del reconocimiento estatal y por lo tanto del reconocimiento social y torna legitimo demandar y exigir, sin estar sujetos a represión y violencia. Sin embargo ello no es suficiente si no se transforma el modo de producción léase capitalismo- que dio lugar al genocidio.

Al mismo tiempo es de esperar que en el contexto actual de mayor visibilidad y reconocimiento, el análisis interdisciplinar contribuya a construir un relato que se acerque a la verdad en términos de reconocimiento de los pueblos indígenas, sus presencias y demandas; un relato que profundice en los condicionamientos del racismo y la colonialidad; un relato que supere la denuncia puntual y que exceda el tratamiento meramente jurídico de los hechos de racismo, etnocidio y genocidio.

Retomando la posición de superar victimizaciones y/o revictimizaciones, no creo necesario exponer a las víctimas al relato público de las vejaciones sufridas. Me atrevo a decir que todos y cada uno de los antropólogos que hemos trabajado largamente con población indígena hemos sido testigos o hemos escuchado relatos de innúmeras situaciones de violación de los derechos de los pueblos indígenas. En ese sentido las demandas de los pueblos indígenas, las denuncias por ellos realizadas y su articulación con el saber antropológico, habilitan a los gobiernos a reconocer que la traumática transformación de las condiciones materiales de existencia, el aniquila-miento, la expropiación de los territorios que libremente ocupaban, el arrinconamiento y la sujeción a mano de obra casi esclava, en pos de la imposición de un "modelo civilizatorio", es etnocidio e implica racismo. Los antropólogos - muchos de nosotros trabajadores del estado, en tanto pertenecientes a universidades y centros de investigación estatalespodemos aportar a este reconocimiento y junto con los referentes indígenas ser tenidos en cuenta por el estado a los fines de avanzar en la materia.

20 de septiembre de 2011.

\section{BIBLIOGRAPHY}

Bartolomé, M. (1987). Afirmación estatal y negación nacional. El caso de las minorías nacionales en América Latina. Suplemento antropológico, vol. XXII Nr. 2.

Bourdieu, P., Passeron, J. C. y Chamboredon, C. (1975). El oficio del sociólogo, México DF: Siglo XXI. Braudel, F. (1969). La historia de las ciencias sociales. Madrid: Alianza.

Escobar, A. (2003). Mundos y conocimientos de otro modo. El programa de investigación de modernidad/ colonialidad latinoamericano. Tabula Rasa. Bogotá - 
Gordillo, G. (1994). La presión de los más pobres: reciprocidad, diferenciación social y conflicto entre los tobas del Oeste de Formosa. Cuadernos. Instituto Latinoamericano de Antropología y Pensamiento latinoamericano.

Grupo de Barbados (1979). Indianidad y descolonización en América Latina. Documentos de la Segunda Reunión de Barbados. México: Editorial Nueva Imagen.

Menéndez, E. (1991). Definiciones, indefiniciones y pequeños saberes. Alteridades, N¹, 21 - 32.

Pacheco de Oliveira, J. (Org.) (1999). A viagem da volta. Etnicidade, política e reelaboração cultural no nordeste indígena. Rio de Janeiro Brasil: Contra Capa.

Quijano, A. (1987). Modernidad, identidad y utopía en América Latina. En: CLACSO 20 AÑOS Imágenes desconocidas. La modernidad en la encrucijada postmoderna

Said, E. (2010 [1978]). Orientalismo. O Oriente como invençao do Occidente. Sao Paulo: Companhia de Bolso.

Sahlins, M. (1977). Economía de la Edad de Piedra. Madrid: Akal.

Tamagno, L. (1986). Una comunidad toba en el Gran Buenos Aires: su articulación social. Actas del II Congreso Argentino de Antropología Social, Buenos Aires.

Tamagno, L. (1991). La cuestión indígena en Argentina y los censores de la indianidad. América Indígena, Vol LI Nr.l Ene/Marzo 1991, 123/152.

Tamagno, L. (1996). Legislación indígena, dificultades para su reglamentación y aplicación: El caso de la Pcia. de Buenos Aires. En: Varesse, Stefano (comp.) Pueblos indios soberanía y globalismo. Quito: Abya Yala.

Tamagno, L. (2001). 'Nam Qom Hueta'a Na Doqshi Lma'. Los tobas en la casa del hombre blanco. Identidad, memoria y utopía. La Plata: Editorial Al Margen.

Tamagno, L. (2002). La historia del genocidio o una historia de genocidios. Coloquio Historia y Memoria. Facultad de Humanidades y ciencias de la educación UNLP. Editado en CD

Tamagno, L. (2008). Diversidad/desigualdad en el espacio nacional. Negación-OcultamientoRacismo-Violencia. En José Nun y Alejandro Grimson (Comps.) Nación y Diversidad. Territorios, identidad y federalismo (pp.63-71). Buenos Aires: Edhasa

Tamagno, L. (2009). Religión y procesos de movilidad étnica. La Iglesia Evangélica Unida, expresión socio-cultural del pueblo toba en Argentina. Iztapalapa Nr. 62 Año 28 Pp. 69-99.

Tamagno, L. (2010). Pensando la nación. Cuestión indígena, cuestión de clase y cuestión nacional. En: Juan Quintar y Carlos Gabetta (Compiladores) Pensar la Nación. Conferencias del Bicentenario. Buenos Aires: Le Monde Diplomatique y Centro Cultural de la Cooperación.

Worsley, P. (1966). El tercer mundo. México DF: Siglo XXI.

\section{AUTHOR}

\section{LILIANA TAMAGNO}

Laboratorio de Investigaciones en Antropología Social LIAS. Universidad Nacional de La Plata, Argentina.

Correo electrónico: letama5@yahoo.com.ar 